\title{
Ornamendi kaitseks
}

Kärt Summatavet

\begin{abstract}
Lihtsad helid äratavad meites igaviku tundmusi, lasevad midagi kõrgemat, tundmata aimata. Kui sarnased virgutused ja aimdused võimalikud on, siis on üks parem, täielikum ilm olemas, millest nad pärit... Kui me kasvada ja edasi ehitada tahame, siis küll ainult - oma p õ l i s e h ä ä alusel.

Kristjan Raud, Oli ennemuiste nõnda, Eesti Kultura I, 1911
\end{abstract}

Paljude põlvkondade vahendatud visuaalsete tekstide kogum kannab rahvakunsti abil meie kultuuriruumi olulisi sõnumeid inimeseks olemise igivanast kogemusest. Nüüdisaegne folkloorikäsitlus peab pärimuse (sh rahvakunsti) kujundajaks ja vormijaks inimese loovust ja fantaasiat. Uuenduslik ja oluline rõhk on asetunud esemete ideetasandile ehk inimese osale esemetes. Rahvakunstis säilinud visuaalsetel kompositsioonielementidel (märgid, sümbolid, ornamendid) on arhailine ja ajas vägagi kaugele ulatuv struktuur ning tähenduskihistused.

Nüüdisaegses uurimuses annab välitöö keskse rolli empiirilisele kontaktile uuritavaga. Et paljusid tänapäeval huvipakkuvaid küsimusi pole kogujad informantidelt õigeaegselt küsinud, ei ole võimalik täpsustada ega sügavamalt uurida vastuseid, sest nende teadmiste kandjad on juba siitilmast lahkunud. Lauri Honko järgi suhtus varasem uurimine seletustesse sageli tõrjuvalt, pidades informandi seletusi kehvemaks kui tegelikke pärimusteoseid (Honko 1998: 60).

Kultuurisemiootilisest lähtekohast vaadatuna on rahvakunst suulise kultuuri tekst. Rahvakunstis kasutatavaid sümboleid, visuaalseid kujundeid, ornamente, märke ja värve ei osata tänapäeval enam seletada, kuna selliste visuaalsete üleskirjutuste lugemiseks vajalikud teadmised puuduvad. Harjumuspäraselt kergekäeliselt lükatakse kõrvale võimalus ornamenti ja märke üldse seletada. Samuti on levinud arvamus, et empiirilise uurimise võimaluse puudumise tõttu ei ole võimalik neid tekste enam tõlkida. Rahvakunst, selle ornament ja märgisüsteem on sellise mõtteviisi 


\section{Kärt Summatavet}

kohaselt tõesti minevikku unustatud tarkusteraamat, mille sisule ja sõnumile lähenemine on nüüdseks juba võimatu, kuna puudub vajalik kood ja tõlkemehhanism. Teisalt on rahvakunstis leiduvate sümbolite tõlkimine siiski võimalik, kui vaadelda rahva loomingut tervikliku nähtusena ning käsitleda olulisi seoseid, rahva suulist ja visuaalset loomingut kui tervikteksti. Inimene ja tema looming on terviklik süsteem, mille osi ei või üksteisest nii jäigalt eristada, nagu eelnenud sajandite uurijad seda on teinud (Summatavet 1994). Inimene, kes tegi käsitööd, laulis samal ajal ka laule, jutustas muinasjutte ning kandis endaga uskumusi ja rituaalsesse kombestikku kuuluvaid tõekspidamisi, mida ta kasutas loomulikus keskkonnas üheaegselt nii profaanses kui ka sakraalses ruumis. Kui Urmas Sutrop peab oluliseks maailmapildi uurimist keelepsühholoogia (keelemälu) ja rahvapsühholoogia seisukohast ning arvab, et rahvatarkust ja rahva kadunud maailmapilti saab kokku korjata ainelise rahvakultuuri säilinud esemetest või vaimse rahvaloomingu mitmetest vormidest, nagu rahvalaulud, muinasjutud, muistendid ja vanasõnad (Sutrop 1999: 114), siis on meie rahvapärimuse vananenud stereotüüpide ümberhindamise tegelik algus tema sõnade abil juba tehtud.

Miks on meie kultuuriruumis uuenduslikud just need uurimused, mille abil avanevad teated selle kohta, mida keel mäletab? Kuidas on selle abil võimalik rekonstrueerida esivanemate rahvatarkust ja maailmapilti? Kui uurime maailmapilti keelepsühholoogia (keele mälu) ja rahvapsühholoogia vaatenurgast, võime kunagi märkamata jäänud olulise informatsiooni, mille kohta omal ajal otseseid teateid üles ei kirjutatud või ei peetud oluliseks, uuesti üles leida juba olemasolevas talletatud materjalis esinevate fragmentide põhjal ning märgata seni uurimata olulisi seoseid. Kuigi mentaalne maailmapilt on uurijaile ja kunstnikele ehk kõige huvitavam, on ta ka kõige raskemini tabatav valdkond. Sutropi järgi kuuluvad mentaalsesse maailmapilti niisugused mõisted nagu ise, hing, vaim, meel, jumal jt (Sutrop 1999: 113). Mentaalsesse maailmapilti kuuluvaid nähtusi on mitmetel põhjustel (ideoloogilised, poliitilised jt) olnud võimalik uurida oluliselt vähem kui muid eluvaldkondi, sest siia kuuluvad nähtused on seotud inimese vaimsuse alustega. Tõeliselt salajasi mõtteid ja kogemusi niisama lihtsalt võõraste inimestega (ka uurijatega) ei jagata. Maailmapilt on peale üldiste tõekspidamiste seotud kindlasti inimese väga isiklike kogemuste ja emotsiooni- 
dega, mida on teiste eest varjatud. Selline isikliku ruumi uurimus ja analüüs meil eestlaste kohta tegelikult puudub.

Kust siis võime veel leida seda isiklikku maailmapilti, mille kandjad on siitilmast juba ammu lahkunud? Vastus on lihtne loomingust, nii suulisest kui ka ainelisest. Loomingu visuaalselt kõige mõjusamaks valdkonnaks on ornament, märgid ja värvid. Enamasti ei ole endisaegsed kogujad küsinud, kas ja mida mõtlesid, uskusid kujutavat või kirjutasid ühe või teise märgi, kompositsiooni või värvilahenduse tegijad? Kas geomeetriline ornament on üks arhailisimaid teksti kirjutamise vorme? Visuaalne keel on nähtav keel. Geomeetrilised tekstid sisaldavad väga arhailisi teateid. Visuaalsete tekstide abil andis suulise kultuuri inimene edasi oma tõekspidamisi, kogemusi ja kujutlusi. Geomeetriline ornament on suulise kultuuri kiri.

Et geomeetrilisi märke ja ornamente on kogu maailmas uuritud lünklikult, siis tavaliselt piirdutakse uurimustes vaid loodusvorme, loomi ja linde kujutavate zoomorfsete ornamentide elementide analüüsiga. Geomeetrilisi märke seostatakse uurimustes enamasti ornamenteerimise ja dekoreerimisega. Eesti varasemad rahvakunstiuurimused käsitlevad ehtimist, ehete kandmist ja rõivaste kaunistamist rahva esteetiliste tõekspidamiste ning kunstimeisterlikkuse tõestusena (Kaarma \& Voolma 1981: 14). Elle Vunder on rõhutanud muu hulgas, et "esteetilisuse ürgne omadus endale tähelepanu tõmmata andis kaunistatud esemetele peale otsese kasulikkuse ja nähtava märgilisuse tihti ka teatava varjatud sümboolse ehk kommunikatiivse väärtuse" (Vunder 1998: 518). Tänapäevase etnoloogia seisukohast on antud väide siiski vähekaaluv, sest "esteetilisuse ürgne omadus endale tähelepanu tõmmata" ei anna esemetele veel mingit varjatud sümboolset ehk kommunikatiivset väärtust. Esteetilisus iseenesest on siiski vaid ornamendi visuaalne aspekt. Ornament on lähemal vaatlemisel midagi sügavamat ja salapärasemat. Ornament esineb kindlate tõekspidamiste ja normide kogumina.

Kui kirjaliku kultuuri teadvust huvitavad põhjuslikud seosed ja toimingute resultatiivsus, siis suulise kultuuri sihiks on kord ja igaveseks antud tekstide korduv taasesitamine (Lotman 1999: 79). Juri Lotmani järgi on suulise mälu maailm tulvil sümboleid. Materiaalsete esemetega esitatud mnemoonilis-sakraalsed sümbolid ei lülitu mitte sõnalisse teksti, vaid rituaali teksti. Suulise kultuuri kirja osa täidavad mnemoonilised sümbolid - nii loodus- 


\section{Kärt Summatavet}

likud kui ka inimese loodud (Lotman 1999: 80). Ornament on siinjuures maagilis-mnemooniliste ja rituaalsete sümbolite ahel (Lotman 1999: 85). Lotman tõi näitena Sokratese, kes pidas suulise kultuuri tekstide unustamise põhjuseks kirja leiutamist (tähestik). Sokratese meelest oli kiri ja kirja leiutamine mälule kahjulik: "See leiutis toob ju nende hingedesse, kes seda on õppinud, unustuse, sest nad hülgavad mälu ning usaldades kirjapandut, meenutavad väliste, võõraste märkide põhjal, ja mitte seestpoolt, inimesele toetudes." (Lotman 1999: 86.)

Mare Kõiva järgi on rahva uskumuste taga sümbolkeel, tavaliselt visuaalselt väga mõjusad kujundid. Sümbolid taasloovad end inimestes, toimib n.-ö geneetiline mälu, mille kohaselt inimene intuitsiooniga taasloob, leiab ja ühendab need ise tähendusega kokku (Kõiva 1999). Ka Kristjan Raud rõhutas süvenemise ja pühendumise vajadust, et mõista endisaegset mõttemaailma: "Iseenese otsinguks, süvenemiseks iseendasse peame teadma, et kõige haruldasem ja kallim vara peitub meis enestes. Seda tuleb püüda eelkõige toimetada päevavalgele. Kuid ainult üksikud vähesed, kes suudavad omil jalul püsida ja oma sisemist elu jätkata, jaksavad tungida möödunud aegade tuumani ja seda hingestatult ja orgaaniliselt siduda nüüdisaja nõuetega.” (Raud 1938.)

Suulise kultuuri vormi- ja sümbolite keel annab märkide, värvide (must, valge, punane, sinine, kollane), ornamentide, materjalide (kuld, hõbe, vask, pronks, raud, puu, kivi) ja kompositsioonilise ülesehituse kaudu edasi nii looja isiklikke kui ka rühma arusaamu nähtavast ning nähtamatust maailmast kompleksse tervikuna. Peale nähtava maailma kujutamise on kunsti eesmärk nähtamatu maailma sobitamine meile arusaadavasse ja nähtavasse vormi (Summatavet 1997: 17). Ehete ja ehiste valmistamisel on oluline inimelu seisukohalt tähtsate piiride, kategooriate ja opositsioonide esile toomine. Ornamendid ja ehtimine on inimesele ka vajalike teadmiste hankimine, korrastamine ja edastamine. Need teadmised on väärtused, mida ei muudeta kergekäeliselt. Rõivastuses on tihti iidsed geomeetrilised kujundid säilinud muutumatul kujul sajandeid, sest inimese ja tema piiride tähistamisega seotud sakraalne sfäär on konservatiivne.

Juba muinasaegse rõivastuse kaunistustes on kasutatud geomeetrilist ornamenti.

Paljusid geomeetrilisi märke ja motiive (ruut, rist, romb, haakrist, E-, S-, V-kujundid, kolmnurk, viisnurk, kaheksakand jne) esi- 
nes juba muinasajal eestlastel, liivlastel, soomlastel, karjalastel, samuti balti hõimudel, aga neid võib kohata ka idapoolsete hõimurahvaste maride, mordvalaste ja komide rõivastuses. Vöödes ja paeltes, kuid ka pronksspiraalidest põiminguis esineb sageli näiteks haakristornamenti, mis on alates pronksiajast levinud kogu Euroopas (Laul 1997: 35). Üks meie vanimaid geomeetrilise ornamendiga tekstiilileide on 11. sajandist pärinev Siksali naisesärgi kaunistus. Silvia Laulu järgi on Siksali särgi varrukasuul ja -päral säilinud geomeetriline ornament, mis on kootud särgi linasesse labasesse kangasse musta ja punase villase koelõngaga (korjatud kirjas). Selle särgi arhailine lõige ning varrukasuu ja -pära kaunistamise komme on Lõuna-Eestis olnud kasutusel veel 20. sajandi alguses. Siksalist leitud 12.-14. sajandi naistesärkidelt pärinevate kaela tagant üle õlgade jooksvate sissekootud geomeetriliste kirjade kajastuse leiame setu särkidelt (Laul 1997: 34).

Tänan Teid, Vana Tark Naine. Teid kohtamata 1983. aastal Lombovozi külas Handimaal poleks käesolevat artiklit sündinud. Fotol: V. Sainahhova. Foto: Kärt Summatavet

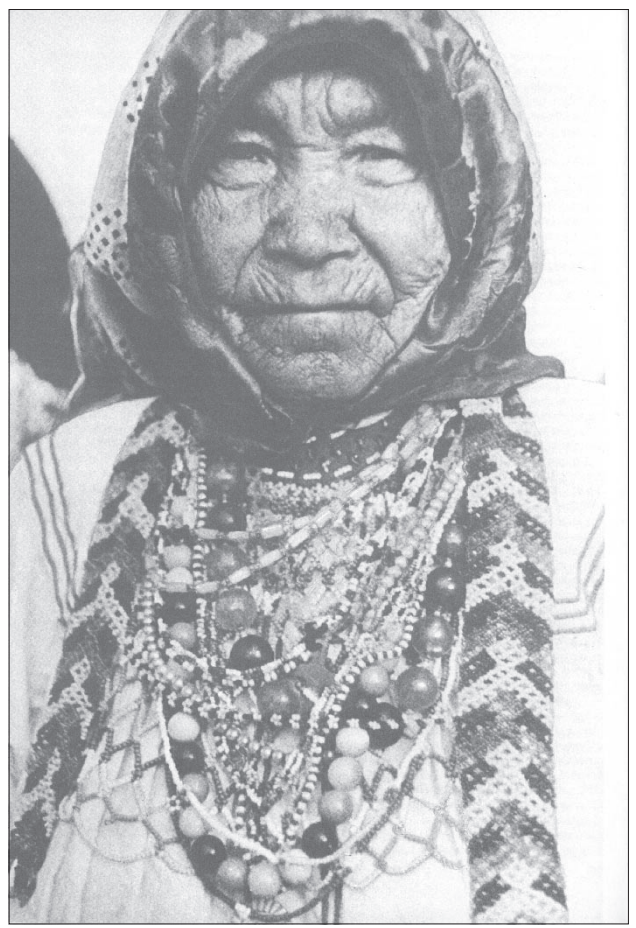




\section{Kärt Summatavet}

Ildikó Lehtineni järgi on rõivastel ja ehetel kaitsefunktsioon, kus igal osakesel on oluline tähendus. Ehted ja ehised on tunnistus inimese ja rahva väärtuste maailmast. Tikitud ja ornamenteeritud ehiseid ei tehta igaühe tujude järele, vaid sellega on tihedalt seotud kindel reguleeritud normistik. Töömahukas tikand on kohustus, milles peitub kaitsev jõud. Hädaohte suudetakse sel juhul tõrjuda maagiliste võtete abil, millest üks oluline võte on ehtimine. Seetõttu on näiteks särkide rinnaesise ehistikandi kujundid ja tehnika püsinud kaua samasugustena (Lehtinen 1997).

Ornamenti kasutatakse kõige levinumalt rõivaste "aukude" ümber. Ornament on piir rõiva kandja kaitsmiseks võõra, tundmatu ja ohtliku eest. Ornamendil on piiri loomise otstarve inimese ja teda ümbritseva ruumi vahele, oma ja võorra, siinpoolse ja teispoolse vahele. Ornament ning ornamenteeritud ese on sakraalse ja profaanse piir ja ühendus, orienteerumisvahend pühas sfääris. Rõivaid on kasutatud ka ühenduse loomiseks (n šamaanikostüümi kandjal tekib side teispoolsusega, ühendus katkestatakse kostüümi seljastvõtmisega; vöö või muu riietuseseme pahempidi pööramisel luuakse ühendus teispoolsusega, parempidi kandes on sama ese aga kaitsev piir teispoolsuse kontakti või agressiooni eest).

Ildikó Lehtineni meelest on rahvariiete uurimuses kahjuks valitsenud üsna pealiskaudne suhtumine, sest riietumise ja kummalistegi rõivavormide põhjusi ning põhimõtteid ei küsitud, neist tehti välitöödel vaid mõningaid tähelepanekuid ja märkmeid (Lehtinen 1999: 10). Lehtineni järgi on riietus teade kandjalt vaatajale. Riietusega tahetakse tugevdada minapilti, kuuluvust teatud rühma ja samas ka erinevust muust rühmast (Lehtinen 1999: 8).

Rahvakunsti ei saa eraldada uskumustemaailmast ja rituaalidest, mistõttu märke ja ornamenti ei ole võimalik vaadelda kui lihtsalt dekoori. Rahvakunsti tuleb vaadelda kui kompleksset struktuurilist tervikut rahva tõrje- ja kaitsemaagilistest, ravi-, arvu-, värvus- ning nimemaagilistest tõekspidamistest (Summatavet 2000). Lotman on märkinud, et rituaalides kasutatavad maagilised märgid rakendavad enamasti geomeetrilisi põhikujundeid - ringi, risti, rööpjooni, kolmnurka (Lotman 1999: 84). Ornament, märgid ja värvid on olulised nii inimestevahelises kommunikatsioonis kui ka rituaalses kommunikatsioonis teispoolsusega. Siinkohal võiks visuaalset kunsti võrrelda itku ja itkemisega. Vaike Sarve järgi on rituaalile iseloomulik kommunikatsioon kui sümbolitele tuginev suhtlemisprotsess. Itkemine on läänemeresoome 
üleminekurituaali üks tähtsaim osa: itkemine annab surnutele rituaalset abi uues olukorras kohanemiseks ja võimaldab mõjutada teispoolseid, et nad ei häiriks elavaid. Itkemine on olnud kaunilt korrastatud ja selge lõpuga tegevus, mis ei lõhu inimese sisemist tasakaalu, vaid pigem ehitab seda uuesti üles (Sarv 1999: 47).

Üleminekurituaalide itkudes pöörduti ka teiste tähtsate olendite poole. Morvalaste pulmakombestikus itkeb mõrsja keskööl talu õue keskel oleva "puhta" ehk "püha" paiga juures ning tema itk on suunatud algul talu haldja ja seejärel surnute poole (Hämäläinen 1913: 55).

Üleminekurituaalides kasutatavatel ornamentidel, märkidel ja värvidel on enamasti tõrjemaagiline funktsioon. Mari pulmas kaitses ornamenteeritud pruudirätik mõrsjat kurja silma eest (Lehtinen 1995: 222). Mordva pruudi pea kaeti ristide ja nelinurkadega kaunistatud kangaga (Hämäläinen 1913: 77). Rituaaliga seotud kunsti kaudu püüti mõjutada teispoolsust. Tõrje-, ravi-, värvus- ja arvumaagilisest seisukohast oluliste märkide, ornamentide, värvide ja arvude "õige" kasutamine on rahvakunsti üks peamisi kompositsioonilise struktuurilise ülesehituse alusprintsiipe.

Nagu eelpool nimetatud, on inimelu seisukohalt tähtsate üleminekurituaalide puhul tõrje- ja ravimaagias kasutatud peamiselt geomeetrilisi märke või ornamente. Märke joonistati nii haigele kohale, õhku kui ka paberile ning neid võidi kasutada koos sõnade või loitsudega. Märk oli seejuures teatud abi- ja mõjutusvahend, ühendus- või tõrjevahend. Mare Kõiva järgi saatsid loitse tegevused (haiguskolde piiramine, ristimärgi joonistamine haiguskolde ja/või ravimi peale) (Kõiva 1995: 186). Maagilised märgid on arstimis- ja tõrjeriitustes loitse lausa asendanud, kuivõrd nõiamärki ja tähtvormelit võib mõneti samastada (Kõiva 1998: 208).

Kogu rituaalne tegevus ja märkide kasutamine toimub siin ühtse tervikuna, kus igal detailil on terviklikust kompositsioonist tulenev kindel sõltuvussuhe teiste toimingute ja märkidega. Eesti Kirjandusmuuseumi kogude põhjal leidub loitsudega ravimise kohta kogutud materjalides teateid, mille kohaselt on joonistatud märke õhus ka haiguskolde kohale (ERA II 138, 404 (8) < Torma (1937), joonistatud paberile (ERA III 23, 145/7 (4) < Elva < Tarvastu) või kasetohule (E 33474 (31) < Otepää).

Rahvakunsti kompositsioonilises ülesehituses on olulisel kohal arvumaagia. Siinjuures võime jälgida sarnasusi loitsudes esineva 


\section{Kärt Summatavet}

arvumaagiaga. Mare Kõiva järgi on loitsudes arvumaagial eriline koht ning numeraalid on vanimaid nõidussõnaliike. Eesti loitsudes prevaleerib kolm (3), kolm korda kolm ehk üheksa (9), kolm korda üheksa ehk kakskümmend seitse (27) ja muud nende arvude kombinatsioonid (Kõiva 1999: 128). Harvem kasutati seitset (7), kümmet (10), kahteteistkümmet (12), üheksakümmend üheksat (99) ja sadat (100) (Kõiva 1999: 117). Mihaly Hoppali järgi on igas kultuuris omad pühad arvud $(3,4,7,9)$, mida kasutatakse nii rahvameditsiinis kui ka sümbolravi eesmärgil rituaalides (Hoppal 1995: 121).

Visuaalsel kujutamisel võib algselt olla ka nimemaagiale viitav aspekt. Nimemaagia seisukohast on oluline, et nimetatud asja, nähtuse või olendiga saadakse "õige" nime nimetamisel ühendus. Seetõttu on nimetamine olnud range kogukondliku kontrolli all (karu, ussi, hundi nimetamine ei ole karjas ja metsas lubatud, kui ei taha just neid kohale meelitada; hooletu nimetamine toob onnetust jne). Nimetamisel saadakse nimetatava üle kontroll (ravi- ja tõrjemaagias laialt levinud võte) või võim. Inimese profaanse argise maailma ja sakraalse püha maailma vahel luuakse kontakt ning nähtamatu maailm kujustatakse ja muudetakse kättesaadavaks. Ühendusega vastastikune sõltuvussuhe ning korrastatus.

Üheks nimetamise vormiks on nime kirjutamine või joonistamine (sh märkide abil) visuaalse vormelina (ka peremärgid). Ornament ja märk on nähtamatu muutmine nähtavaks. Märk on samavõrdne kujuga ehk visuaalsel kujul esitatud olendi või nähtuse nimega ning esindab tema nime ja olemust visuaalselt. Iga visuaalne korrastatus nõuab teatavaid kompositsioonilisi reegleid, tõekspidamisi, ülesehituspõhimõtteid, teatud visuaalsete detailide kasutamist kompositsioonilises tervikus.

Tänapäevases põhjahandi kunstis eksisteerib rida mustreid, millel on teada nende tähendus. Tatjana Moldanova jagab need mustrid kahte rühma: pühad mustrid ja maagilised ornamendid. Pühasid mustreid leidub rituaalsetel esemetel (kinnastel, mütsidel, vöödel). Argipäevadel on pühad mustrid keelatud. Pühad mustrid kujutavad endast kaitsevaime ja neid kasutatakse ainult rituaalsetel eesmärkidel. Moldanova järgi peetakse pühade mustritega esemeid sakraalseteks, s.t pühas mustris usutakse olevat teatud jõud, energia, mis on võimeline puhastama, pühitsema eset ja seejärel hoidma seda antud olekus. Maagilised orna- 
mendid erinevad pühadest märkidest selle poolest, et neil on tõrje- ja kaitsemaagiline funktsioon ning neid kujutatakse ka igapäevaselt tarvitusel olevatel esemetel. "Silmale nähtamatut" eristatakse reaalsetest objektidest kujutamise stiili poolest (Moldanova 1995: 270-272).

Ornamentide puhul on oluline ka värv. Värvide kasutamistihedus ning tähendusjõudlus on erinev ning vastab enamasti teatud normidele. Mare Piho arvates on värv inimese vaimse kogemuse tulemus, samas selle kogemuse fikseerimise ja süstematiseerimise üks esimesi vorme (Piho 2000: 1). Värvi tähendus kui tekst, sõnum, märk on mõistetav nii piiritletud kasutajaterühmale kui ka nendele, kes puutuvad kokku tähendust teadva ja teistega teadmisi jagava rühmaga. Esmased ja universaalsed värvid on valge ja must ning punane. Punast ja valget kasutati kõige sagedamini üleminekurituaalides, sinist ja musta surmakombestikus. Punane kaitseb elavaid inimesi ning on hädavajalik sünni-, pulma-ja surnukommetes. Eesti ravimaagias on levinud värviliste lõngadega haiguskolde piiramine või ümbritsemine punasega, kasutati ka sinist ja musta. Sinine, must ja valge on tuntud matmiskombestiku värvidena, punasest surnu puhul hoiduti. Mare Piho ütleb raamatus Punane ja valge. Setud. Värv ja kultuur: "Olla valges rõivastuses tähendab setude jaoks olla õiges vahekorras nii elavate kui surnutega, seega olla terve, kahjustamata ning kurjast puutumata. Setudel tähistab valge ka seaduslikust, kokkukuuluvust ja traditsiooni, samuti on valge setude leinavärv." (Piho 2000: 2.) Vastsündinud mansi lapsele (Lombovoźi küla) seoti kaitseks punastest klaashelmestest kee kaela või käe ümber. Vanasti kasutati sealsamas punaste helmeste asemel kaitseks ka punaseid marju (pihlakas, kibuvits) (Summatavet 1983: 6). Põhja-handid keerasid oma juuksepalmikute ümber siniseid või punaseid villaseid paelu. Villapaelte värvil oli oma tähendus: tavaliselt kanti punast; sinist kanti omakse surma puhul (Lehtinen 1979: 82). Setudel võib punane tähendada nii head kui ka halba, kusjuures ta seostub päikese, tule ja verega. Punane on seotud aktiivse seisundi, sündimise, jõu ja elujõuga, kuid võib tähistada ka hääbumist, kadu, tapmist ja isegi surma (Piho 2000: 6).

Kas ja miks kasutatakse ravimisel ja tõrjemaagias ornamenti? Märk, loits, nimi ja kuju on olnud võrdväärse mõjujõuga, kusjuures neid on kasutatud ka üksteise asendajatena. On teada rida esemeid, mida on kasutatud nii ravi- kui ka tõrjemaagilistel ees- 


\section{Kärt Summatavet}

märkidel (pulmakindad, surnukindad, kingitustena antavad kindad üleminekurituaalide puhul). Haiguste raviks kasutatakse ka geomeetrilise ornamendiga vöösid. Varasematest uurijatest on ka Elle Vunder maininud, et haiguste ravis on laialdaselt teateid selle kohta, et ravimisel kasutati kirjatud vöid, kindaid ja sukki (Vunder 1998: 519). Vöö ornamenti on seostatud arusaamadega vöö maagilistest omadustest. Eevi Astel väidab oma raamatus Eesti vööd, et geomeetrilise ornamendiga vööd on kasutatud haiguste ravimisel veel hiljuti, sest Eesti Rahva Muuseumi kogudes on haruldane $c a 3 \mathrm{~m}$ pikkune Urvastest pärit vöö, mida on teadaolevalt 20. sajandi algul "nõiduse juures tarvitatud" (Astel 1998: 19). Kui Eevi Astel vaid mainib, et vööd on kaunistatud vanade, maagiliste sümbolitena tuntud geomeetrilise ornamendi elementidega, nagu kolmnurgad, rombid, ristid (Astel 1998: 20), siis Juri Lotman peab geomeetrial põhinevaid märke teistest märkidest erilisemateks, sest lihtsa väljendusega sümbolitel on palju suurem kultuurilis-tähenduslik maht kui keerulistel. Risti, ringi, pentagrammi tähendusjõudlus on väga suur. Juri Lotmani meelest moodustavad just "lihtsad" sümbolid kultuuri sümboolse tuuma ja nendega küllastatuse määr võimaldab otsustada, kas kultuur tervikuna on sümboliseeriva või desümboliseeriva suunitlusega (Lotman 1999: 225).

Eesti iidseimaid traditsioone säilitanud kultuurialadel - Setumaal ja Kihnu saarel - nimetatakse ornamenteerimist, mustrite tikkimist ja kudumist kirjutamiseks. Sümbolite, märkide, värvide, ornamentide keele abil kirjutatakse üles suulise kultuuri teated ning tekstid. Rahvakunst on suulise kultuuri üleskirjutatud tekstide ja sõnumite kogum, mida võib vaadelda kui oma maailma loomist, sümboolset kosmose (korrastatuse) loomise püüet. Maailma korrastatust ei tohtinud kunagi unustada, mistõttu kordamine (rituaal, kunst, laul, jutt, tants) tagas mäletamise. Siinjuures märkide, sümbolite ja värvide abil organiseeriti ja korrastati kaost. Kõik, mis on ornamendita, on võõras, ohtlik ja kontrollimatu. Kõik oma nimetatakse, kujutatakse, lauldakse, tantsitakse, ehitatakse ning kinnistatakse enda omaks loominguprotsessi kaudu. Loominguprotsessi tulemus aitab hoida lahus oma ja võõrast või säilitada ühendust oma ja võora vahel nii esemelises, ajalises kui ka ruumilises plaanis. Loomingu kaudu kinnitatakse piirid oma ja võõra ning siinpoolse ja sealpoolse vahel. Samuti nagu loomad märgistavad oma territooriumi, märgistab inimene oma loomingu (sh 
rahvakunsti, ornamentika, märgid, värvid, arvud, nimed) abil oma ja võõra piirid ning kodustab territooriumi nii materiaalses kui ka vaimses mõttes.

EHE JA EHTIMINE on inimeseks olemise igivana kogemus. Ornament on unikaalne nähtus, mis on omane ainult inimkultuurile. Ornament teeb inimesest inimese ja eristab ta nähtava maailma muudest nähtustest, kuid samas loob piiri ja ühenduse inimesele nähtamatu sakraalse maailmaga. Rahvakunsti olemuse ja sõnumi mõistmiseks ja lugemiseks peame rahvakunsti vaatlema kompleksse struktuurilise tervikuna ning kompositsioonilise ülesehituse puhul süvenema rahvakunstis peituvatesse tõrje- ja kaitsemaagilistesse, ravi-, arvu-, värvus- ning nimemaagilistesse tõekspidamistesse (Summatavet 2000). Ehtimise ja ornamenteerimise eesmärk on suulise kultuuri inimeseks olemise kogemuse üles kirjutamine. Rahvakunst on kõige iidsem ja arhailisem üleskirjutatud tekstide kogum meie minevikust, olevikust ja tulevikust.

\section{Kirjandus}

Astel, Eevi 1998. Eesti vööd. Tartu: Ilmamaa.

Honko, Lauri 1998. Folklooriprotsess, Mäetagused 6. Tartu.

Hoppal, Mihaly 1995. Sümbolravi Ungari rahvameditsiinis. Hiiemäe, M. \& Kõiva, M. (toim). Rahvausund tänapäeval. Tartu.

Hämäläinen, Albert 1913. Mordvalaisten, tsheremissien ja votjakkien kosinta- ja häätavoista. Vertaileva tutkimus. Helsinki: SKS.

Kaarma, Melanie \& Voolma, Aino 1981. Eesti rahvarõivad. Tallinn: Eesti Raamat.

Kõiva, Mare 1995. Loitsust riituseni. Hiiemäe, M. \& Kõiva, M. (toim). Rahvausund tänapäeval. Tartu.

Kõiva, Mare 1998. Tähtvormelid. Sator I. Tartu.

Kõiva, Mare 1999. Rahvakunsti alused. Eesti Kunstiakadeemia loengusari, sügissemester 1999. Käsikiri autori valduses.

Kõiva, Mare 1999. Numeraalid. Ühest loitsude alaliigist. Eesti Rahva Muuseumi aastaraamat XLIII. Tartu: Eesti Rahva Muuseum.

Laul, Silvia 1997. Muinasesti rõivastus ja rahvarõivad. Lee 4. Tartu: Eesti Rahva Muuseumi Sõprade Selts "ÜMIN".

Lehtinen, Ildikó 1979. Naisten korut Keski-Venäjällä ja Länsi-Siperiassa. Helsinki: Museovirasto.

Lehtinen, Ildikó 1995. Mari naiste olukord. Maride pulmariietus. Congressus Octavus Internationalis Fenno-Ugristarum, Pars VI Ethnologia \& Folkloristica. 


\section{Kärt Summatavet}

Lehtinen, Ildikó 1997. Kirjonta selviytymiskeinona. Pirta, 4. Helsinki. Lehtinen, Ildikó 1999. Marien mekot. Volgansuomalaisten kansanpukujen muutoksista. Helsinki: Suomalais-Ugrilainen Seura.

Lotman, Juri 1999. Semiosfä̈̈rist. Tallinn: Vagabund.

Moldanova, Tatjana 1995. Pühad ja maagilised mustrid kaasaegses põhja-handi ornamentaalses kunstis. Congressus Octavus Internationalis Fenno-Ugristarum, Pars VI Ethnologia \& Folkloristica Jyväskylä.

Piho, Mare 2000. Punane ja valge. Setud. Värv ja kultuur. Tartu: Eesti Rahva Muuseum.

Raud, Kristjan 1911. Oli ennemuiste nõnda. Eesti Kultura I.

Raud, Kristjan 1938. Süvenemisest. Tartu: Kunstiühing Pallas.

Sarv, Vaike 1999. Itkud üleminekurituaalis. Teater. Muusika. Kino 5.

Summatavet, Kärt 1983. Manside ehted. Tallinn: ERKI õppeekspeditsiooni teaduskonverentsi ettekanne. Käsikiri autori valduses.

Summatavet, Kärt 1994. Soome-ugri käsitöö ja sümbolite keel kaasaegse käsitöö inspiratsiooni-allikana. Savitaipale: ettekanne Europeus Akatemia rahvusvahelisel konverentsil "Nainen kansantaiteessa ja kansanrunoudessa".

Summatavet, Kärt 1997. Soome-ugri rahvaste vana maailmapildi põhisümbolitest ja nende kasutamise võimalustest tänapäeva kunstiloomingus. Lee 4. Tartu: Eesti Rahva Muuseumi Sõprade Selts “ÜMIN".

Summatavet, Kärt 2000. Hõimukalender 2000/ Heimokalenteri 2000. Tallinn.

Sutrop, Urmas 1999. Meie esivanemate rahvatarkus ja maailmapilt: mida keel mäletab? Mäetagused 11 .

Vunder, Elle 1998. Rahvakunst. Viires, A. \& Vunder, E. (toim). Eesti Rahvakultuur. Tallinn: Eesti Entsüklopeediakirjastus. 